\title{
SMA-Based System for Environmental Sensors Released from an Unmanned Aerial Vehicle
}

\author{
Lorenzo Pellone ${ }^{1, \dagger}{ }^{+}$, Salvatore Ameduri ${ }^{2, *,+}$, Nunzia Favaloro ${ }^{3, \dagger}$ and Antonio Concilio ${ }^{2, \dagger}$ \\ 1 Aeronautics Systems Engineering Department, Centro Italiano Ricerche Aerospaziali, \\ Via Maiorise, Capua 81043, Italy; 1.pellone@cira.it \\ 2 Adaptive Structures Department, Centro Italiano Ricerche Aerospaziali, \\ Via Maiorise, Capua 81043, Italy; a.concilio@cira.it \\ 3 Space Propulsion Facilities, Centro Italiano Ricerche Aerospaziali, \\ Via Maiorise, Capua 81043, Italy; n.favaloro@cira.it \\ * Correspondence: s.ameduri@cira.it; Tel.: +39-823-623-556 \\ + These authors contributed equally to this work. \\ Academic Editor: Rafic Ajaj \\ Received: 10 October 2016; Accepted: 18 January 2017; Published: 24 January 2017
}

\begin{abstract}
In the work at hand, a shape memory alloy (SMA)-based system is presented. The system, conceived for releasing environmental sensors from ground or small unmanned aerial vehicles, UAV (often named UAS, unmanned aerial system), is made of a door, integrated into the bottom of the fuselage, a device distributor, operated by a couple of antagonistic SMA springs, and a kinematic chain, to synchronize the deployment operation with the system movement. On the basis of the specifications (weight, available space, energy supply, sensors size, etc.), the system design was addressed. After having identified the main system characteristics, a representative mock-up was manufactured, featuring the bottom part of the reference fuselage. Functionality tests were performed to prove the system capability to release the sensors; a detailed characterization was finally carried out, mainly finalized at correlating the kinematic chain displacement with the SMA spring temperature and the supplied electrical power. A comparison between theoretical predictions and experimental outcomes showed good agreement.
\end{abstract}

Keywords: shape memory alloy springs; UAV; sensor release

\section{Introduction}

In the recent years, the research and development of unmanned vehicles have gained much attention in the academic and military communities worldwide. Systems like unmanned aircraft, underwater exploiters, satellites, and intelligent robotics are widely investigated as they have potential (dual) applications both in the military and civil domains. They are developed to be capable of working autonomously, without a human pilot. One of the main challenges is the need to deal with extremely varying situations that arise in complicated and uncertain environments, like unexpected obstacles and enemy attacks [1].

UAV (unmanned aerial vehicles) is an acronym for a wide class of aircraft, ranging from a few centimeters to many meters in wingspan, from simple, hand-operated units to high altitude, long endurance systems similar in operation to manned aircraft. In the literature they are classified as RPA (remotely piloted aircraft), AAV (autonomous aircraft vehicles), and so on [2-6]. A UAV is defined as an aerial craft, flying without human crew on-board; it can be remotely controlled or fly autonomously [6,7]. Over the past three decades, the popularity of UAV or UAS (unmanned aerial systems-in 2005, the U.S. Department of Defense, DoD, started defining them as "flying systems") has kept growing at an unprecedented rate. Among different types, small-scale UAVs are gaining interest and popularity because: 
- They are a powerful tools for scientific research due to attractive features such as low cost, high maneuverability, and easy maintenance. Significant progress has been made in various investigation areas (e.g., dynamics modeling, flight control, guidance, and navigation);

- They can be implemented in many dangerous civil applications, like emergency monitoring, victim search and rescue, aerial filming, geological survey, weather forecast, pollution assessment, fire detection, and radiation monitoring.

The development of UAVs has been strongly motivated by military applications. Indeed, their development dates back to the development of the first aerial torpedoes, almost 95 years ago. During World War I (WWI), both the Navy and the Army experimented aerial torpedoes and flying bombs. These first examples highlighted two operational problems: for instance, crews had difficulty in launching and recovering the UAV; there were several problems in stabilizing them during flight, and so on. Efforts continued through the Korean War, when military services experimented with UAV with different missions, sensors, and munitions, in attempts to provide strike and reconnaissance services to battlefield commanders.

At those times, numerous obstacles have hindered the evolution of the UAV. Firstly, technology simply was not mature enough for them to become operational. Secondly, lack of service cooperation usually led to failure. Currently, the main showstoppers include mostly non-technical issues, such as lack of service enthusiasm, overall cost effectiveness, and competition with other weapons systems (like manned aircraft, missiles, space-based assets, and so on). In this frame, small-scale UAV seem an ideal choice for collecting information with zero casualties involved [8], at minimal implementation costs. Moreover, they seem to position into a segment with no real competitors, simply giving a novel service. They assume a unique role to warfare and defense, as for close-range surveillance and reconnaissance in confined battlefields or urban environments.

In the framework of the Military National Research Program (MNRP), and thanks to Aerosekur cooperation, CIRA (the Italian Aerospace Research Centre) has carried out a feasibility study of a small parafoil-equipped UAS for patrolling, intelligence, surveillance, reconnaissance, and telecom networking. The system is characterized by an excellent transportability and a quick configurability. Its relatively simple architecture is sketched (Figure 1-left), where the sail and the fuselage outlines are shown. The target sensor dimensions are also reported (Figure 1-right). The main features are summarized in Table 1:
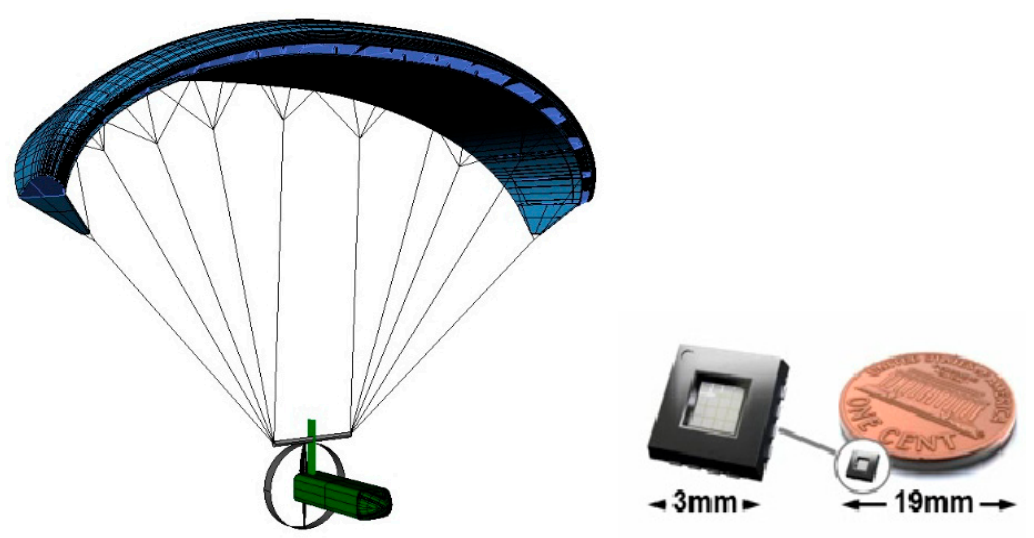

Figure 1. UAS ((unmanned aerial systems) sketch (left); atmosphere sensor dimensions (right).

Table 1. UAS main features.

\begin{tabular}{cccc}
\hline Sail Span $(\mathbf{m})$ & Sail Area $\left(\mathbf{m}^{\mathbf{2}}\right)$ & Overall Weight $\mathbf{( k g )}$ & Energy $(\mathbf{W h})$ \\
\hline 1.6 & 2.4 & 5.0 & 38.5 \\
\hline
\end{tabular}


The parafoil (or "sail") is connected to the fuselage by wires. The body hosts the flight control unit, the power supply, the engine, the payload and the landing gear system. All of the components are designed to keep the system mass and size at a minimum and to allow a compact packaging and a rapid deployment on the ground. The target vehicle is conceived to perform missions at low altitude (300 $\mathrm{m}$ at sea level) and limited endurance $(1 \mathrm{~h})$. A typical mission is sketched in Figure 2. It can bring different payloads and sensors, depending on the selected mission (as fixed and mobile targets identification, border patrol, traffic control, and many others, also involving civil applications).

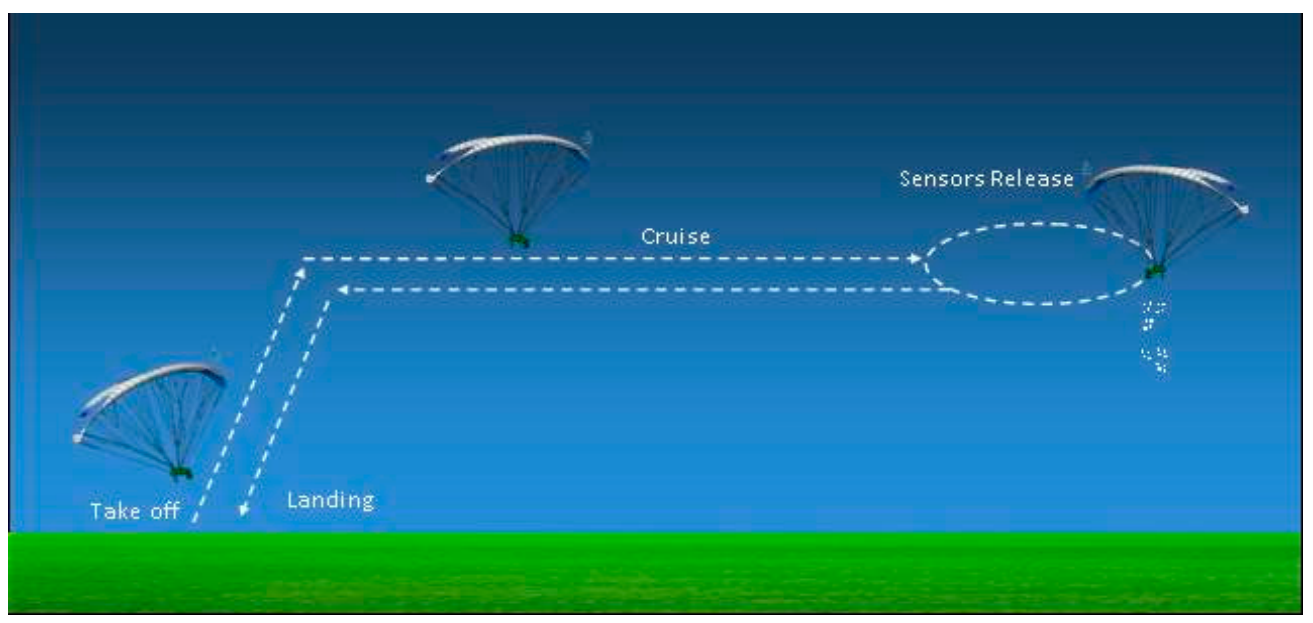

Figure 2. Typical mission of a UAS.

The device presented in this paper is aimed at storing and releasing sensors from the UAV. In this sense, it belongs to the robotic end effector family [9], being in practice an interface between the UAV and the external environment. With reference to the standard classification of gripper-releasing devices (mechanical, thermo-mechanical, negative pressure, magnetic, and so on) [10], it can be identified as a thermo-mechanical system in the sense that it is actuated through shape memory alloy (SMA), whose functioning requires heat supply. Moreover, the device was conceived to be employed for unknown environments. In fact, it is switched on during certain phases of flight, but it does not require any feedback on the status of its task.

SMAs are characterized by the co-existence of two different and distinct states or phases inside the same physical domain, namely martensite and austenite [11]. The switch between these states may be continuous and depends on the stress and temperature levels. Microscopically, these variations are related to a re-arrangement of the crystal structure within the metal while macroscopically they give rise to relevant deformations, ranging up to several unit percentage almost reaching $10 \%$. Together with this effect, some other material features vary, like the damping coefficient (moving from barely $1 \%$ to more than $10 \%$ ) or the Young modulus (in certain cases increasing or decreasing by a factor 3-martensite to austenite, or vice versa). The reported numbers relate to NiTi-based SMA. For other compounds, those qualities may change; nevertheless, they give an idea of their strong potentiality in generating adaptive structural elements. In this article, shape memory alloys springs are used to construct a motor for deploying sensors, taking advantage of both the strain recovery (contraction) and the variable rigidity (stiffening) peculiarity. The non-linear-hysteretic nature of the SMA materials and the combined strong dependence on the applied load and temperature, make the modeling task very challenging and justify the several works focusing on the formalization of constitutive laws [12-14] and on the empirical-experimental characterization $[15,16]$.

The described system has been specifically designed to release environmental (temperature, pressure, etc.) or pollution sensors, in order to get more environmental information. In commerce, there is a quantity of such miniaturized devices, developed and applied by industry, academia and individual innovators. For instance, there are devices able to detect non-methane volatile organic 
compounds (NMVOC) emissions, smoke, and toxic gases, [17]. During the mission, the UAV could work like an antenna, receiving and transmitting real-time data to a ground receiving station, or a data store, using a micro data recorder.

In order to give the UAS some further capability, a simple, affordable, low-cost deployment system was specified. This paper deals with the design of an environmental sensor spreader (ESS). The concept is shown in Figure 3. It is made of a bottom door, an SMA-based sensor mover and a kinematic chain, devoted to ensure the due synchronization between the movement of the different elements and in particular the panel opening (from which the sensor is launched to the ground) and the settler displacement (that pushes the sensor to the door).

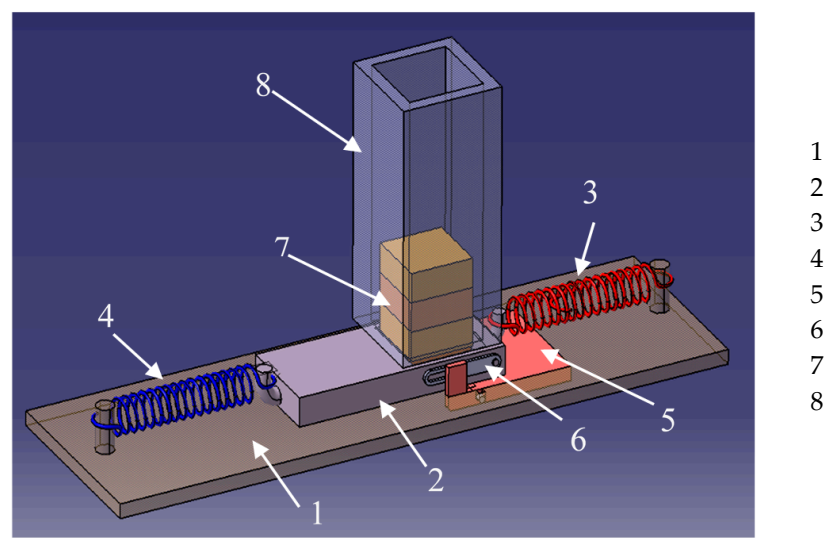

\author{
Base \\ Sensor Guide-Positioner \\ SMA Active Spring (red) \\ SMA Antagonistic Spring (blue) \\ Opening Panel \\ Lever \\ Sensors \\ Sensor box
}

Figure 3. CAD of the environmental sensor spreader (ESS) and its main elements.

SMA actuators permit a strong reduction of the system parts and, then, its complexity. In similar applications, a servo actuator opens the panel $[18,19]$, while another servo actuator grips and releases the objects $[20,21]$. The use of a bulk SMA component simplifies the overall architecture. The penalty that shall be paid for the related efficiency reduction ( 1 to 5 ) is well compensated by the decrease in the number of pieces (a good index for reliability and maintenance), weight savings, and compactness. This advantage can be also exploited for other on-board components like landing gears, deployable antennas and others [22-31].

Different aspects, like the power supply, the weight, the size, and the maintenance, play critical roles and must be carefully taken into account from the early stage of the design of this specific end effector. The application of SMA actuators offers some advantages, proved by several studies and patents [32-35], ranging from the industrial [36], to the medical-surgery [37], the aerospace [38], and the automotive [39], fields. The compactness and the high energy density favor lighter and solid design solutions for instance compliant with the typical aerospace weight and maintenance requirements [40]. The large transmittable forces and displacements well meet often conflicting desiderata, like grasp and deployment specifications, typical of hand-like grippers [32]. The possibility of tuning the electrical signal, used for the SMA heating, makes available a signal for a feedback control, applicable in the low frequency bandwidth [41].

On the other hand, some general drawbacks and limitations must be necessarily considered. The low mechanical efficiency may limit the use of those actuator systems to small applications [40]; the thermal inertia of the material may exclude any dynamic application (practically, $\geq 2 \mathrm{~Hz}$ ); the electrical supply imposes the use of adequate thermal and electrical insulation strategies.

All of these aspects were taken into account during the early stage of the device design. In compliance with the drafted characteristics, the SMA actuators size (here used in the form of springs) were contained. The kinematic chain in charge of opening the panel and moving and dropping the sensor was optimized to assure an adequate movement synchronization and to guarantee a global simplification of the overall system architecture. Finally, the springs were supposed to be directly 
in contact with the calm air contained within the fuselage volume and, thus, in natural convection regime. Force convection strategies would speed up the cooling process, making the release task faster, but would also penalize the system in terms of power consumption (keeping the springs at a lower temperature). Numerical and empirical investigations aimed at enhancing the cooling process through inlets/outlets will be considered in future works with the scope of optimizing the system for specific missions and enhancing the technology readiness level (TRL).

The device development started from an investigation about its functionality, based on geometrical considerations and multi-body simulations. The model reproduced both the positioner translation and the door rotation. A concentrated force simulated the action of an active SMA spring working against an antagonistic SMA spring, whose reaction was estimated through the classic force-displacement curve, experimentally determined. This empirical approach was considered applicable to the device conceptual design task, while more sophisticated models (Finite Element, FE, integrated with dedicated constitutive laws [42,43]) will be taken into account for future works, focusing on the optimization of the different functional parameters. By correlating the active spring displacement to the door rotation, the kinematic frame was set. The force, necessary to achieve a certain configuration, was calculated by imposing the energy balance between the elastic energy stored in the antagonistic spring and the work done by the external actions (i.e., the active spring force and the sensors weight moment, evaluated with respect to the door pivot). Numerical simulations were related to experimental results, obtained through a test campaign on a functional mock-up (Figure 3). The experiments allowed validating the theoretical model and verifying the system functionality; moreover, they permitted drafting a preliminary relationship between the SMA activation temperatures and the system kinematics. Finally, the achieved performance was compared to the original requirements.

\section{Requirements and Specifications}

Referring to the baseline mission scenario "detection and surveillance" (Figure 2), where there is a long cruise segment, the main specifications of the sensor release system were related to the overall size and weight of the hosting UAS. According to the European Cooperation Space Standardization, ECSS, Space Standard, in detail in the System Engineering General Requirements, ECSS-E-ST-10C, and the Technical Requirements Specification, ECSS-E-ST-10-06C, all of the specifications were associated with some attributes, the most important of which was the "traceability". In other words, each single requisite (son) was linked to its generator (parent) inside a specified set. This enables the derivation of a "tree", demonstrating the global coherence of the issues specs. A synthetic block diagram is reported in Figure 4.

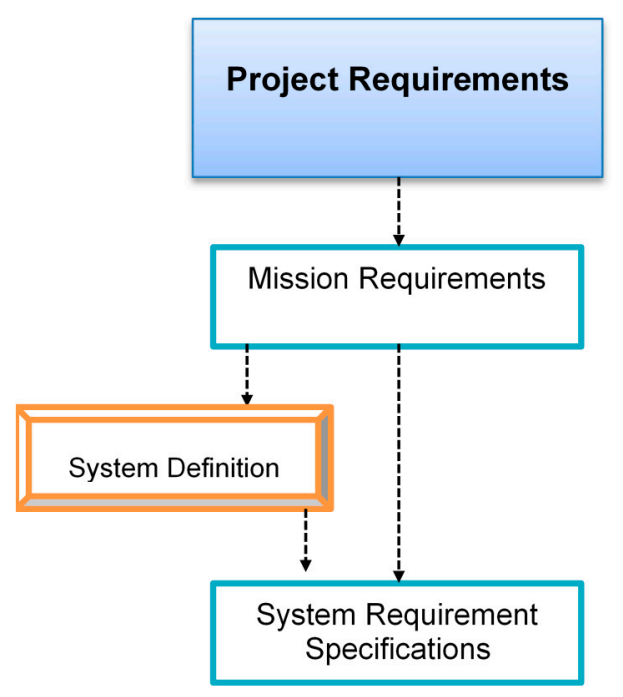

Figure 4. Requirement tree. 
In the studied case, the high-level requirements are following reported. Above all, the system dimensions should have fit with the fuselage size and allow transporting and deploying the maximum possible number of sensors. The system weight should have been compatible with the maximum payload weight defined for the specific UAS and the related mission. Starting from that, the following constraints were defined (sensor size was fixed to $10 \times 2 \times 4 \mathrm{~mm}$ ):

- System dimensions: $\leq 100 \times 30 \times 54 \mathrm{~mm}$

- System weight (without sensors): $\leq 70 \mathrm{~g}$

- Total system weight (including sensor): $\leq 300 \mathrm{~g}$

- Max power available: $\leq 15 \mathrm{~W}$

\section{Working Principle of the Environmental Sensor Spreader (ESS)}

The equilibrium state between the two SMA springs, in turn modulated by their excitation levels, creates a certain ESS system configuration. Its mechanics follows these steps:

Step 1-“Initiation": In this phase, the two SMA springs are in a pure elastic equilibrium (there is no activation by any external source). At their installation, the springs are stretched and connected each other, thus achieving the pre-load equilibrium. Their stretching induces the transformation of the initial full austenite into martensite. To this aim, a material was selected, characterized by a martensite start temperature $\left(\mathrm{M}_{\mathrm{s}}\right)$ very close to the specific environmental conditions. Therefore, the necessary stress increment to induce the desired transformation may be kept at a minimum. On the other hand, it should be mentioned that this limit cannot be fully approached in order to avoid the insurgence of non-commended activations due, for instance, to a hot sunny day.

The martensite fraction, $\xi$, produced during the stretching can be expressed as a function of the curvilinear abscissa along the experimental black curve in Figure 5. There, it shows the force-displacement history the springs undergo when they are integrated into the system. The initial linear slope of the curve corresponds to a classical material behavior, regulated by the austenite Young modulus. As the applied load arises, the gradual transformation into martensite occurs. The transformation process may continue up the phase transformation is completed. In the graph, this is evidenced by a relevant change of the line angle, characteristic of this transitional effect. The higher the martensite fraction in the pre-load condition, the wider the recoverable displacement through the activation. In the pre-load condition, the sensor is ready in the dispenser (guide-positioner, Figure 6 - top). Considering the relation among the rigidity, $K$, of the springs and the wire diameter, $d i$, the winding diameter, $D$, the number of windings, $N$, and the shear modulus, $G$ :

$$
K=\frac{1}{8} \frac{d i^{4}}{D^{3} N} G
$$

and adapting the shear-normal elastic moduli relation to the $\xi$ weighted average of the martensite, $E_{m}$, and austenite, $E_{a}$, Young moduli:

$$
G=\frac{E}{2(1+v)}=\frac{E_{m} \xi+E_{a}(1-\xi)}{2(1+v)}
$$




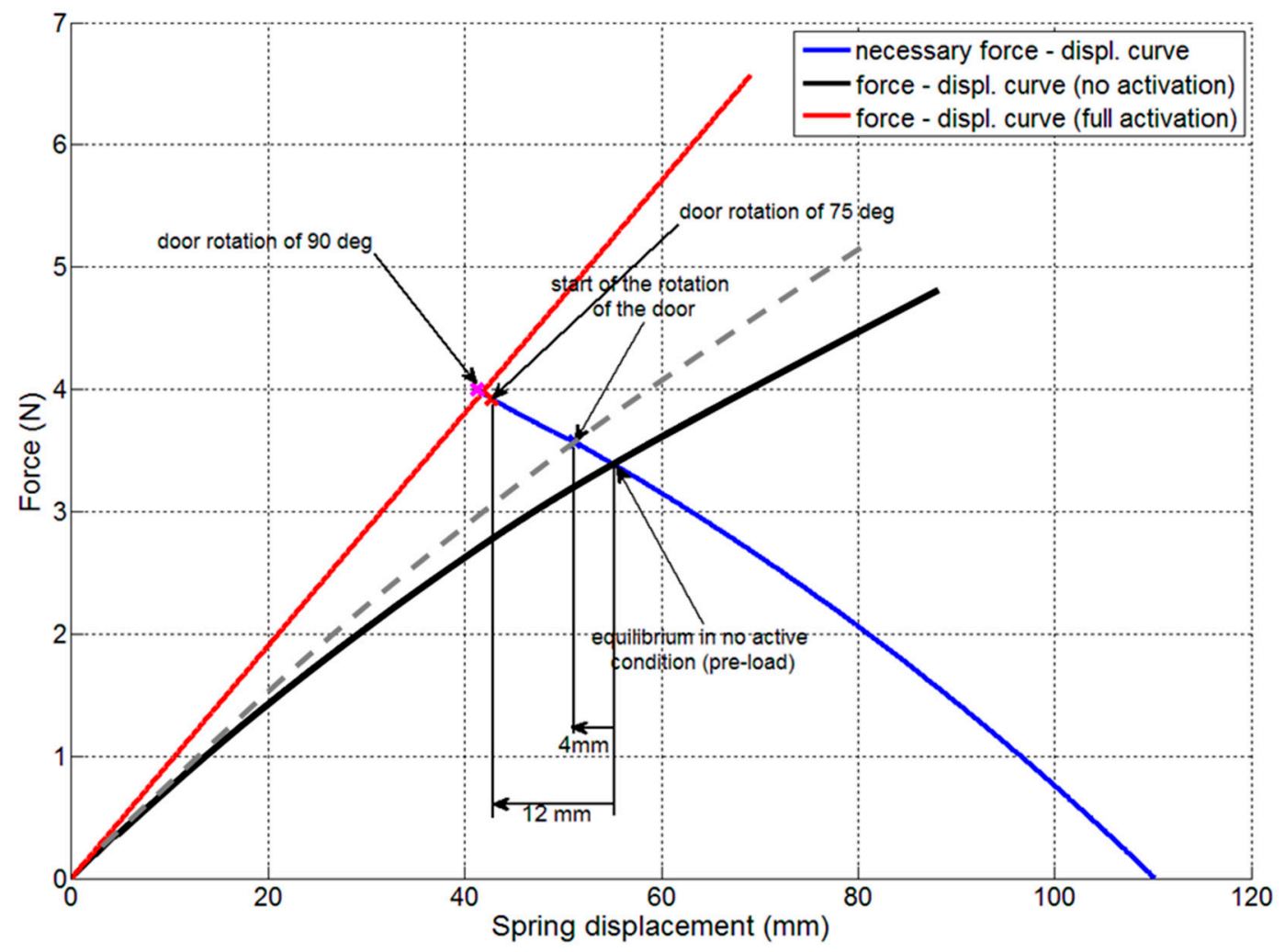

Figure 5. System working points; force displacement curve for the non-activated SMA spring (black); force displacement curve for the fully activated SMA spring (red); intermediate activation curve (dashed); elastic response of the system (blue)

An estimate of the martensite fraction can be obtained at each point of the curve. In particular, $\xi$ results equal to the $85.5 \%$ in pre-load condition. This verification was experimentally performed by releasing the spring after having reached the target elongation. It moves then along a straight line, the slope of which is related to " $K$ ", Equation (1). By using the Equations (1) and (2), an estimate of the effectively achieved $\xi$ is easily produced.

Step 2-"Door opening": It is made of two coordinated movements: a translation of the sensors guide coupled to a rotation of the ejection panel. In particular:

a. At first, the active SMA spring (red in Figure 6) is excited and pulls the sensors guide from position 1 to 2 (Figure 6 -middle);

b. At position 2, while the sensor guide continues its movement, a lever system (Figure 3, component (6) opens the door and allows releasing the sensor (position 3, Figure 6-bottom).

Step 3- "Door closing": Once the sensor is dropped, the active SMA spring excitation is turned off and the antagonist elastic element (blue) returns the system in its original configuration; the process may be accelerated by activating this other spring, in turn. The switch rail is driving backward to close the door. 


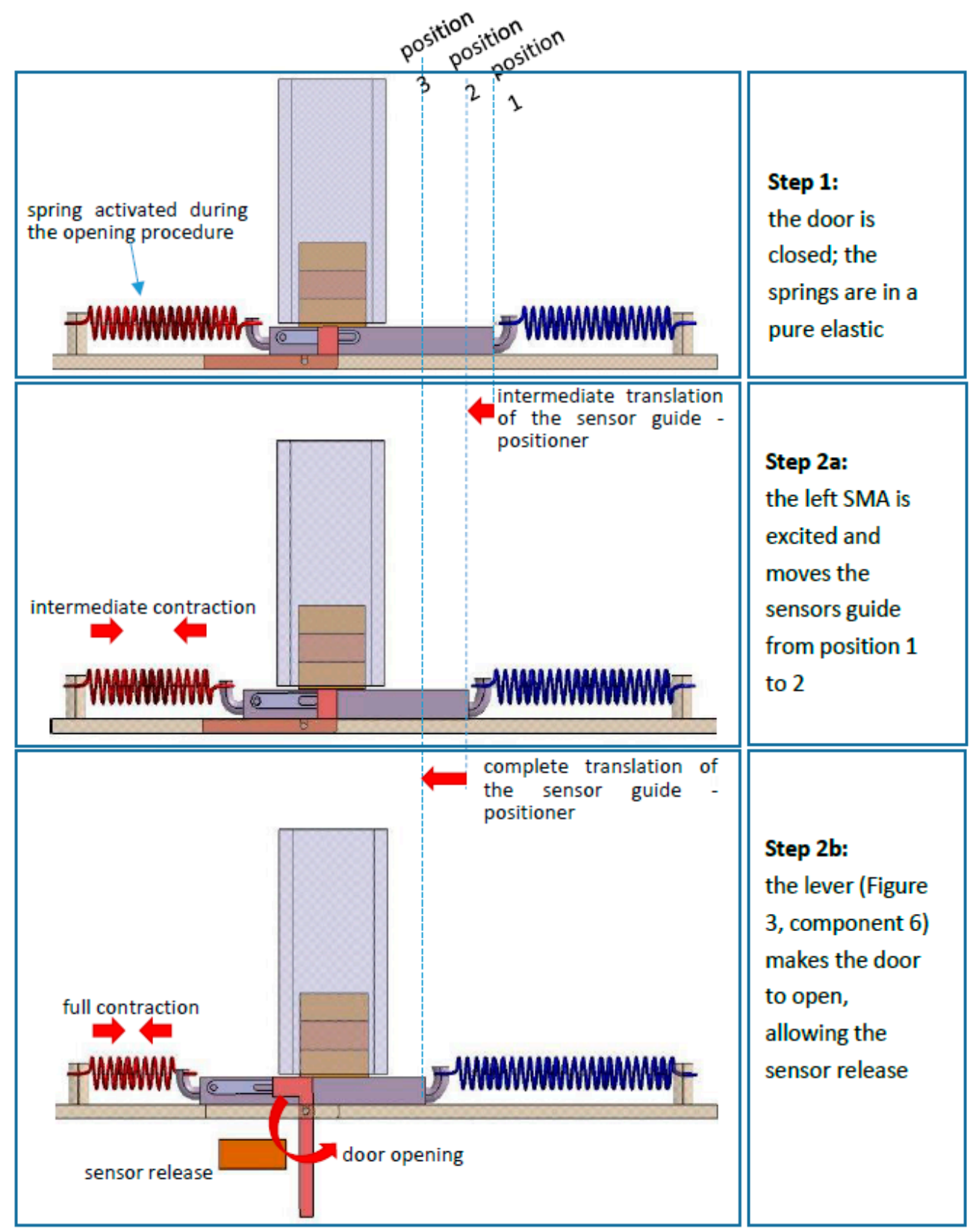

Figure 6. ESS working principle schematic, highlighting the main phases of the sensor's release.

\section{Modeling}

The system was modelled according to the schematic reported in Figure 7. Therein, the "active" red and the "antagonistic" blue springs are shown as a joint in B. The positioner is not sketched; it is linked to the two elastic elements through the point B. As the red spring contracts, it moves to the left, within a slide (grey in the picture). The green segment $\mathrm{AD}$ represents a lever that is rigidly connected to the door, schematized as a further green line from A to the left. This couple is hinged in A, so that a motion of the point $\mathrm{D}$ causes its rotation. The first picture, (a), represents the initial state of the system: a closed door, non-excited and equilibrated springs, with point $B$ at the right slide endpoint. 
a)

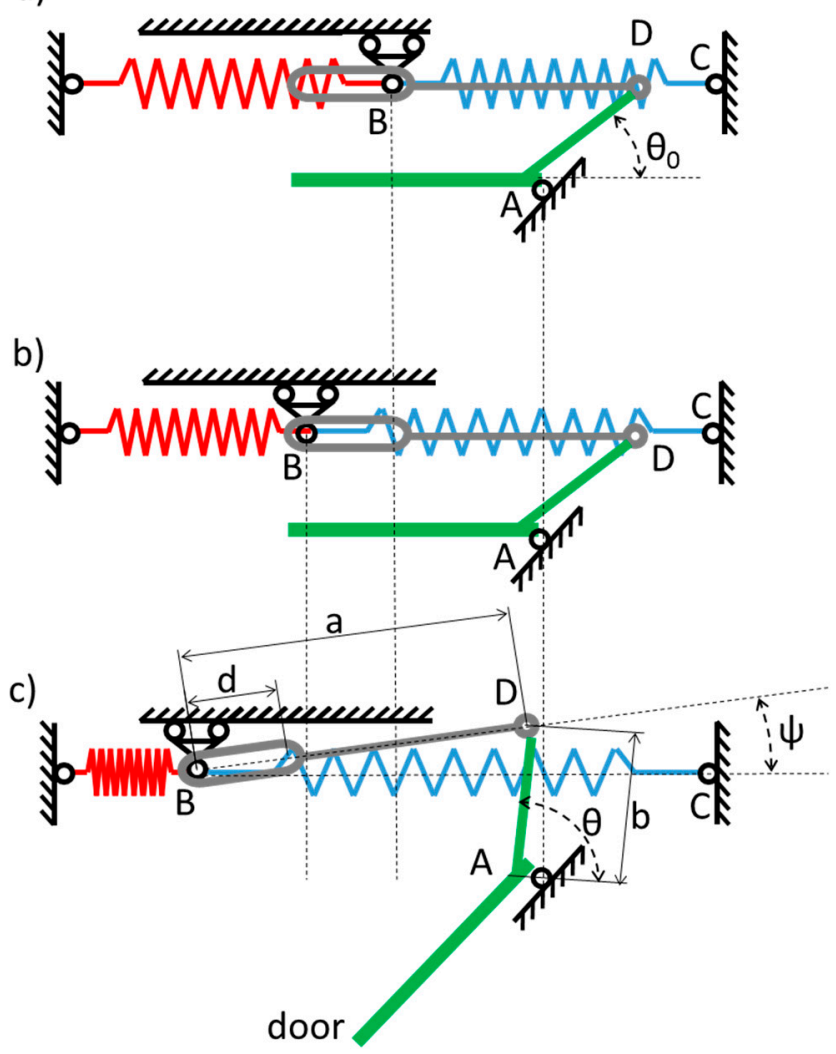

Figure 7. Schematic layout of the proposed device: initial state of the system (a); leftward translation of the point $B$ due to the spring activation $(\mathbf{b})$; rotation of the door $(\mathbf{c})$.

The activation of the red spring produces an initial translation of the point $\mathrm{B}$, which moves to the left slide endpoint (Figure $7 \mathrm{~b}$ ). Since this moment, a further contraction of the red spring forces the motion of the slide to the left; as it is rigidly connected to the point $\mathrm{D}$ (grey line), this causes a rotation of the lever (segment AD) and the door (Figure 7c). It is important to remark that the blue spring and the grey connection are not interfering each other; they are just overlapped in the 1D drawing but they have no point in common. The movement may continue until the left spring reaches its max contraction. A block did, however, limit the door rotation at $75^{\circ}$ from the initial value $\theta_{0}$, following the specifications. In Tables 2 and 3, the main SMA spring parameters and the main overall system features are reported, in order. The selected NiTiNol alloy (Ni 49.8\%) was experimentally characterized. Austenite and martensite Young moduli were determined through tensile tests and Differential Scanning Calorimetry, DSC, measurements at " 0 " load condition after the necessary stabilization cycles. The material underwent tens of mechanical cycles at room temperature $\left(23^{\circ} \mathrm{C}\right)$, and the last most significant cycles, in terms of convergence, are plotted in Figure 8a.

Table 2. SMA spring characteristics [31].

\begin{tabular}{ccccccccc}
\hline $\begin{array}{c}\text { Helix } \\
\text { Diameter } \\
(\mathbf{m m})\end{array}$ & $\begin{array}{c}\text { Wire } \\
\text { Diameter } \\
(\mathbf{m m})\end{array}$ & Windings & $\begin{array}{c}\text { Unloaded } \\
\text { Length, } \\
\mathbf{L} .(\mathbf{m m})\end{array}$ & Material & $\begin{array}{c}\text { Austenite } \\
\text { Young } \\
\text { Modulus } \\
(\mathbf{G P a})\end{array}$ & $\begin{array}{c}\text { Martensite } \\
\text { Young } \\
\text { Modulus } \\
(\mathbf{G P a})\end{array}$ & $\begin{array}{c}\text { Transformation } \\
\text { Temperatures } \\
\text { As, Af, Ms, Mf, } \\
\mathbf{R s}, \mathbf{R f}\left({ }^{\circ} \mathbf{C}\right)\end{array}$ & Density $\left(\mathbf{k g} / \mathbf{m}^{3}\right)$ \\
\hline 5.5 & 0.5 & 23 & 25.0 & NiTiNOL & 103.3 & 57.7 & $\begin{array}{l}65.9 ; 78.4 ; 36.4 ; \\
-3.8 ; 73.7 ; 49.8\end{array}$ & 6450 \\
\hline
\end{tabular}


Table 3. Main system features.

\begin{tabular}{ccccccc}
\hline $\begin{array}{c}\text { Device Shape } \\
(\mathbf{m m})\end{array}$ & $\begin{array}{c}\text { Device Weight } \\
(\mathrm{g})\end{array}$ & $\begin{array}{c}\text { Device CoG } \\
\text { Distance to A }(\mathbf{m m})\end{array}$ & $\begin{array}{c}\text { AC Vertical } \\
\text { Distance }(\mathbf{m m})\end{array}$ & $\begin{array}{c}\text { BC Length, } a, \\
(\mathbf{m m})\end{array}$ & $\begin{array}{c}\text { Slot Length, } \\
\boldsymbol{d}_{\boldsymbol{\prime}}(\mathbf{m m})\end{array}$ & $\begin{array}{c}\text { Initial Angle, } \\
\left.\boldsymbol{\theta}_{0}, \boldsymbol{(}^{\circ}\right)\end{array}$ \\
\hline $15 \times 15 \times 3$ & 10.0 & 7.5 & 5.0 & 70.0 & 4.0 & 45.6 \\
\hline
\end{tabular}

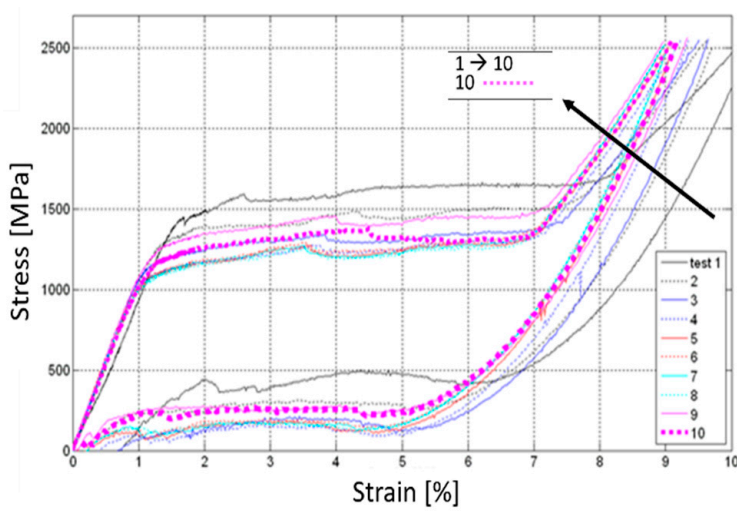

(a)

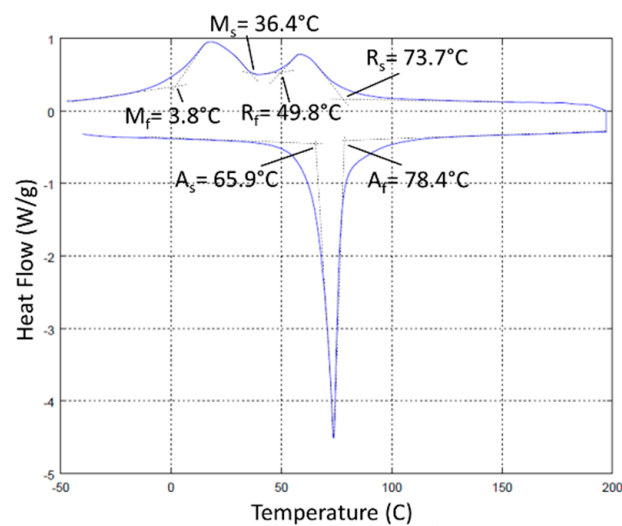

(b)

Figure 8. SMA spring material characterization: tensile cycles (a); and Differential Scanning Calorimetry, DSC, measurements (b).

The modelling started with the formalization of the non-linear relation between the door rotation, $\theta-\theta_{0}$ (respectively, current and initial angles between the lever AC and the ground line), and the point $\mathrm{B}$ translation. These are the main descriptors of the kinematic chain. For displacements that were lower than the slide length, $d$, Figure $7 \mathrm{~b}$, the angle was kept constant at $\theta_{0}$ (closed door). For displacements larger than $d$, a trial value is used to start the iteration to assess the running angle. The equation linking $\psi$, the angle between the slide and the ground line, and $\theta$ can be written as:

$$
\psi=\sin ^{-1}\left[\left(\frac{b}{a}\right) \sin \left(\frac{\theta}{a}\right)-\left(\frac{h}{a}\right)\right]
$$

In the above formula, $b, a$, and $h$ represent the length of the segments $\mathrm{AD}$ (lever), $\mathrm{BD}$ (slider system), and the vertical distance between the point $C$ and $A$, respectively. The relation between the longitudinal displacement of the point $B, x_{B}$, and the angle $\theta$ is, instead:

$$
a \cos \psi-b\left[\cos \theta-\cos \theta_{0}\right]-x_{B}=R
$$

The sign of the estimated residual, $R$, derives from the bisection method that generates a further value for $\theta$ used again in Equations (3) and (4) until convergence occurs $(R \rightarrow 0)$. The resulting rotation-displacement curve is reported in Figure 9, for $\theta$ ranging between $0^{\circ}$ and $90^{\circ}$. Spring displacement is plotted with respect to its equilibrium length (zero displacement corresponds then to $x=54 \mathrm{~mm}$ ). A circular marker highlights this state in the picture. Moving from this point, displacements of $\mathrm{B}$ do not produce any rotation until they are lower than $d$. After that, the door starts opening and the curve leaves the $x$ axis. The spring activation force was computed by expressing the system energy balance, Equation (5). It takes into account the elastic energy stored in the antagonistic spring, left side, the active spring work, first term on the right side, and the work performed by the door weight momentum around $\mathrm{A}$, second term on the right side:

$$
\int_{0}^{s} F_{\text {antag }}(\bar{s}) d \bar{s}=\int_{0}^{s} F_{a c t} d \bar{s}+W r_{c g} \int_{\theta_{0}}^{\Theta(s)} \cos \left(\bar{\theta}-\theta_{0}\right) d \bar{\theta}
$$


In the equation above, $W$ and $r_{c g}$ are the door weight and the distance of its center of gravity from the pivot, in order. The cosine function expresses the variation of the weight momentum arm with respect to $\mathrm{A}$, as the door rotates. $F_{\text {act }}$ represents the activation force, unknown, while $F_{\text {antag }}$ relates the displacement of the antagonistic spring to its reaction. This relation between the applied force and the induced displacement is experimentally determined by measuring the spring displacement caused by different loads.

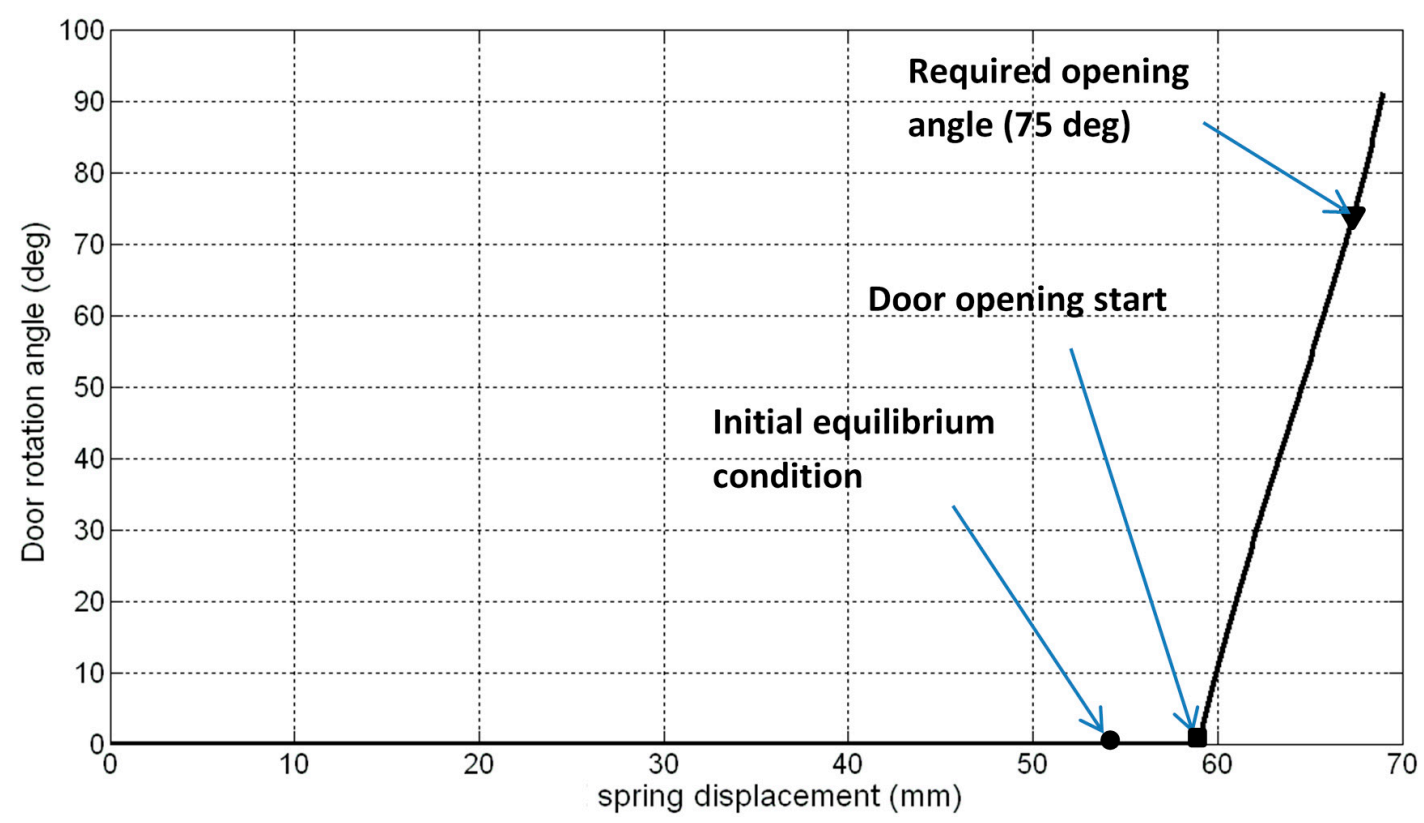

Figure 9. Door rotation vs. super elastic (SE) spring displacement.

Equation (5) can be numerically solved for $F_{a c t}$, in order to relate this parameter to the induced displacement, $x_{B}$. The characteristic system working points (representing the non-activated and the fully-activated states) can be found by displaying three different curves onto a single graph, Figure 5:

- The just-mentioned " $F_{a c t}-x_{B}$ " curve (blue);

- The force displacement curve (black) for the non-activated SMA spring; this curve was plotted at the environmental temperature, $T_{\text {env }}$ : as the load rises, the transformation into martensite is enforced;

- The force displacement curve (red) for the fully activated SMA spring; this curve refers to a pure austenite phase and it was plotted under the assumption the temperature was sufficiently high to keep pure the austenite condition within the entire load range.

Moving from the pre-load point on the black curve ("equilibrium in no load condition"), any rise of the SMA temperature enforces its transformation into austenite, passing through intermediate configurations, like the one depicted by the grey dashed curve. The intersections between the blue and these curves represent initial and final equilibrium points of the global system. Since the pre-load condition is located on the constant slope part of the black curve, it is possible to assume that the spring works, moving from a full martensite condition. Full activation may lead to an $85^{\circ}$ door rotation, well larger than the required one $\left(75^{\circ}\right)$. The device then has good operational margins.

The selected configuration allowed a remarkable simplification of the overall modelling process. In fact, once the two-spring system has been brought to its equilibrium state, the working philosophy moves the operational point up and down along the blue curve that is reported in Figure 5 and was experimentally determined (indeed, the things are a bit more complex as will be explained below). The active spring cycles between a partial martensite (point $\underline{\mathrm{A}}$, Figure 10) and a full austenite state as 
its temperature grows (point $\underline{B}$, Figure 10). At the cooling, the active spring mutates again and comes back to a partial martensite phase.

This description is strictly valid if a classical antagonistic elastic spring is considered. Since this last element is also made of the same shape memory alloy, after having moved from the initial point $\underline{\mathrm{A}}$ to the working point $\underline{B}$, the forced reverse transformation does not occur according to the blue curve, Figure 5. Instead, because austenite is created, the return happens along a different, more inclined slope, Figure $10(\underline{B} \rightarrow \underline{C})$. As this other component cools, however, the working point moves up again to the initial one $(\underline{\mathrm{C}} \rightarrow \underline{\mathrm{A}})$.

Furthermore, the segments $\underline{\mathrm{BC}}$ and $\mathrm{CA}$ should not be considered as straight, but as part of curves, characteristic of the SMA change of phase. This takes place in theory. In the practical application, from one side the two segments are practically coincident and, on the other side, this event does not add any particular information. Then, for the scope of the present work, this behavior complication may be neglected (i.e., segments $\underline{\mathrm{AB}}$ and $\underline{\mathrm{BC}}$ are hardly distinguished and may be considered straight) and the system may be described by the curves already illustrated in Figure 5.

For the reader's benefit, an ordinated description of Figure 10 is reported. The equilibrium state, $\underline{A}$, is reached at temperature $\mathrm{T} 1$. The active spring is then warmed to temperature $\mathrm{T} 3$ (T2 is an intermediate value). The working point then moves from $\underline{A}$ to $\underline{B}$. When the active spring is cooled and the antagonistic spring is excited, the working point moves from $\underline{B}$ to $\underline{C}$, according to the partial to full austenitic characteristic (curve $\mathrm{BC}$ ). As the antagonistic spring also cools, the working point again approaches the original point $\underline{\mathrm{A}} \underline{\mathrm{AB}}$ and $\underline{\mathrm{BC}}$ are not namely straight lines but they are represented in that way for the sake of clarity.

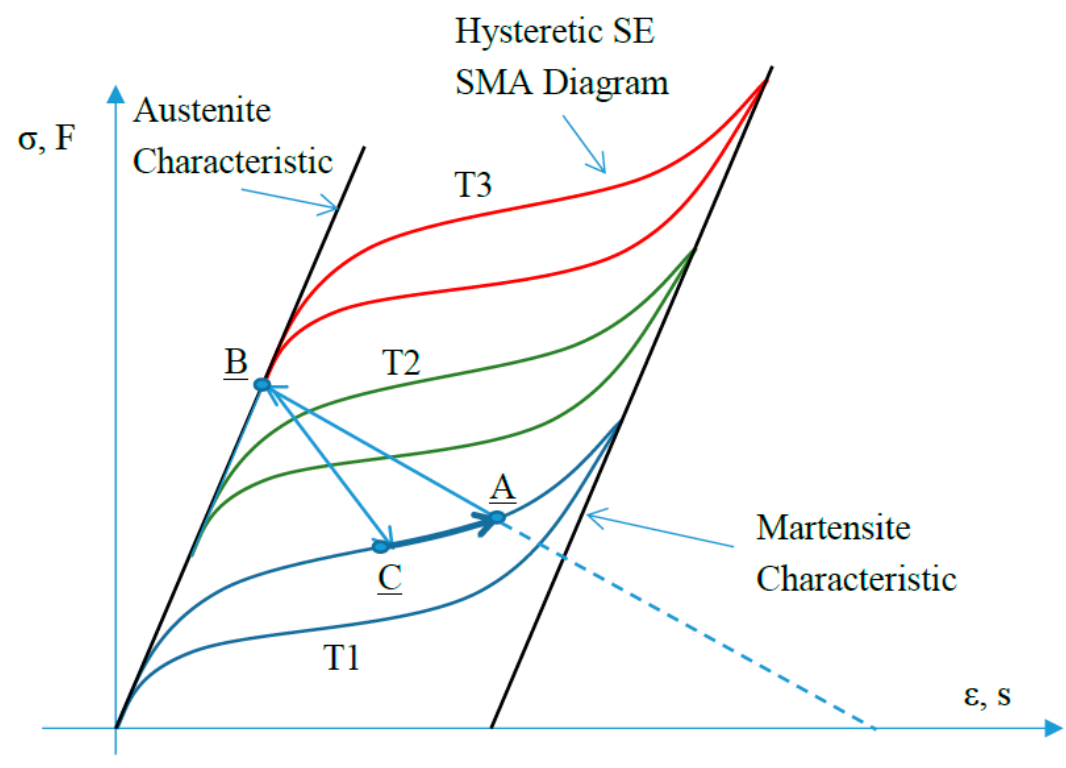

Figure 10. Theoretical behavior of a two-spring SMA system.

\section{Manufacture and Test}

A conceptual prototype was then realized (Figure 11). A dedicated experimental campaign was organized with the double aim of appreciating the real system ability in deploying the sensors and monitoring the main device parameters like the spring temperature and displacement, the door rotation, the supplied energy, and so on. In particular, two different test campaigns were performed:

- Functionality tests, aimed at verifying the system operation;

- Monitoring tests, for characterizing the device state and correlating the various descriptors. 


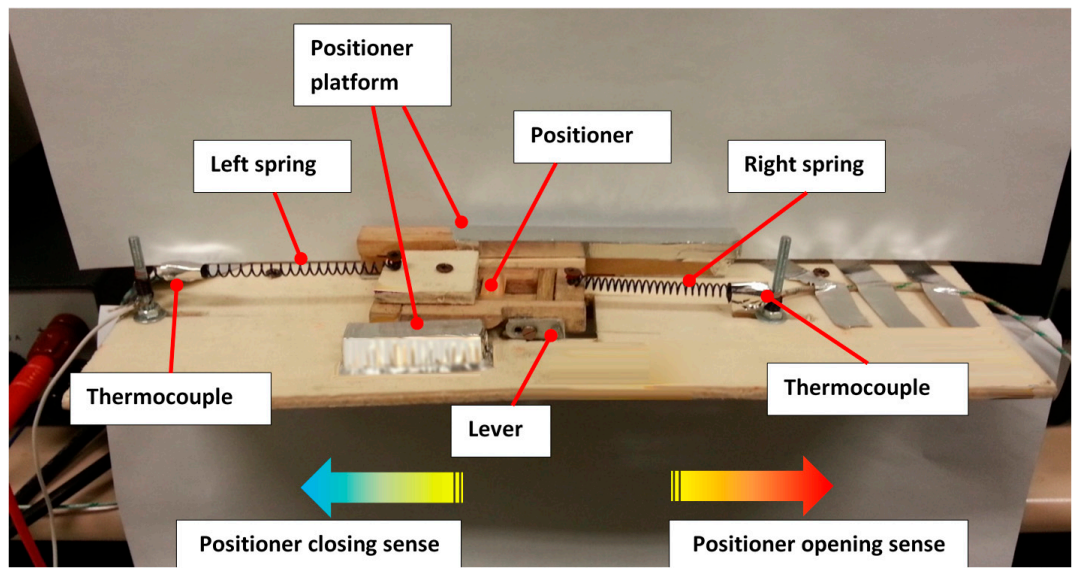

Figure 11. Prototype main components.

Pictures of the setup block diagram and the experimental setup are shown in Figures 12 and 13, respectively. The following instrumentation was used:

- The prototype of the sensor release system, Figure 11, clamped on a supporting structure;

- A four channel, $24 \mathrm{MHz}$ signal generator, for the generation of the logical signals, necessary to drive the power suppliers that fed the SMA springs;

- Two power supplies, operating within 0-30 V and 0-10 A current ranges;

- An oscilloscope, dedicated to monitor the driving logical signals;

- An acquisition system, to manage and store the output analogic signals (50 ms sample rate);

- Two "K-type" thermocouples;

- A digital camera to take pictures of the system, during the experiments.

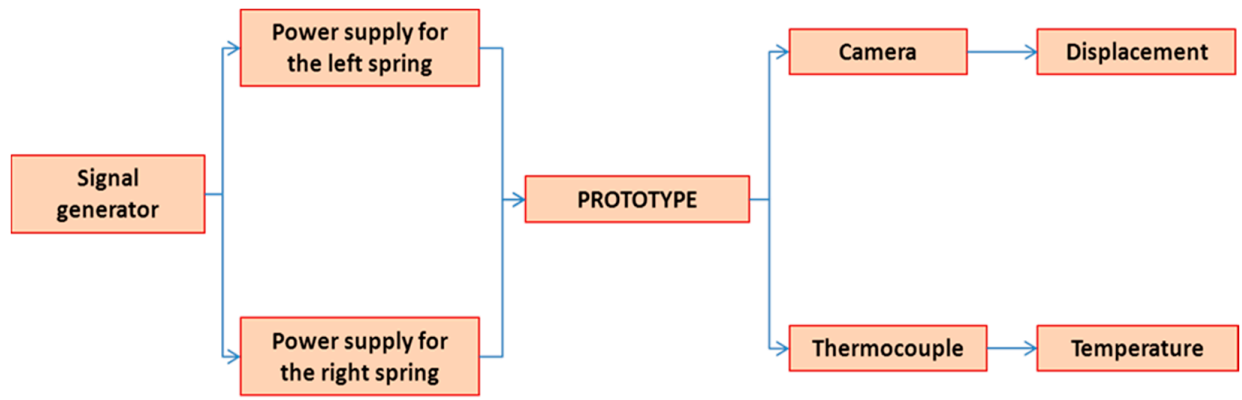

Figure 12. Setup block diagram.

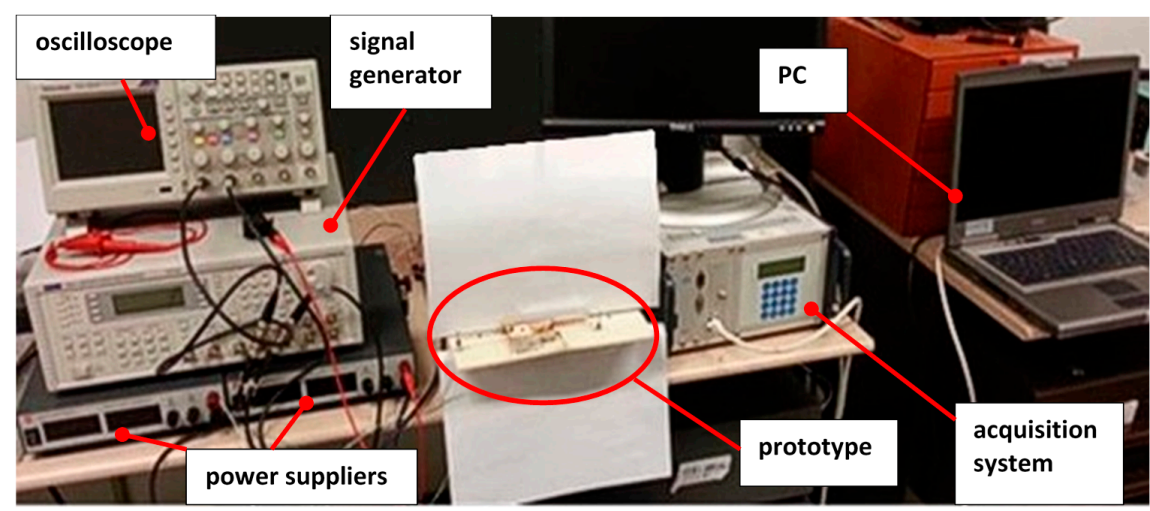

Figure 13. Experimental setup. 
Both the functionality and the monitoring tests were performed by activating both of the springs, alternately. The operations were structured as follows. Two anti-phase logical step signals were produced to drive the active and antagonistic springs, separately. The two power suppliers were then activated in turn (Figure 14). Each complete cycle (activation-deactivation) took $100 \mathrm{~s}$ and the springs were heated for $5 \mathrm{~s}$. The power supplies provided a current of $2.5 \mathrm{~A}$ under a voltage of $1.2 \mathrm{~V}$, corresponding to $3 \mathrm{~W}$ per spring (Direct Current, DC).

An example of the performed functionality tests is shown in Figure 15. Therein, a sequence of video shots details the door opening and the sensor release. At first, the sensor moves horizontally, pushed by the positioner (first frame: start of the cycle; second frame: positioner moved and door ready for rotation). Then, the door starts opening (third and fourth frames: intermediate door rotation and start of the sensor drop). Finally, the sensor is released (fifth frame). The system operability was then proved. The vertical dashed line indicates the initial location of the positioner. A system characterization was then carried out for evaluating the main working parameters. The system was driven for several cycles. Two thermocouples monitored the spring temperature, while the camera captured different states of the working device. In Figure 16, the activation signal, the temperature and the corresponding displacement are plotted along a complete activation-deactivation cycle for both the SMA elements over a period of $1.8 \mathrm{~min}$.

The complete operation may be divided into two segments, each 0.9 min long. The first is related to the contraction of the left spring and its following subsequent freezing in this condition (door opening-pink area); the second refers instead to the contraction of the antagonistic SMA that brings the device back to the initial configuration (door closing - light blue area). In detail, the temperature of the left spring arises from the environmental condition up to $82{ }^{\circ} \mathrm{C}$ (Figure 16-top). A certain inertia of the power supply could be observed for around $6 \mathrm{~s}$, since the spring temperature continued growing even after it was switched off (dashed vertical lines, Figure 16-top). The contraction started at the early supply start, as shown by the corresponding displacement curve (black): from 6.30 to $6.35 \mathrm{~min}$, the length of the left spring passed from 10.1 to $1.0 \mathrm{~mm}$. A specular behavior was observed for the right elastic element, Figure 16-bottom, since they are connected to each other and as the one shrinks, the other stretches.
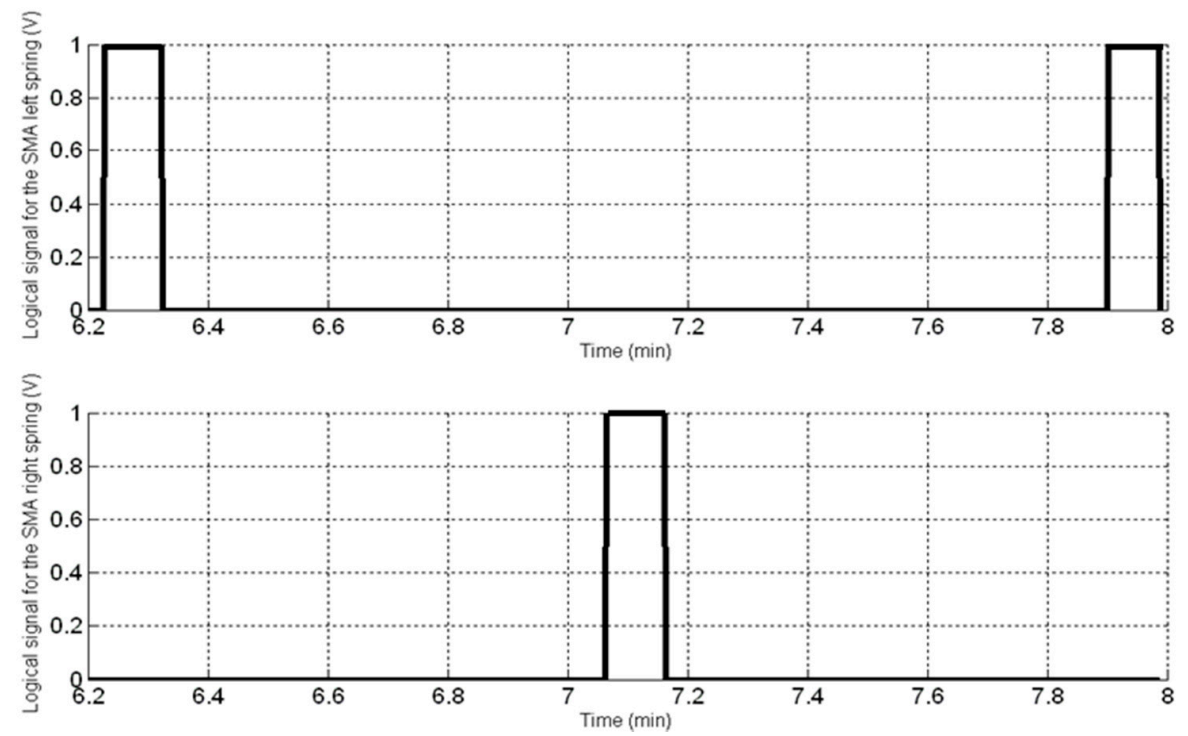

Figure 14. Logical signals to drive the power suppliers.

The sensor release is accomplished as the active SMA fully shrivels ("spring recovery" label, Figure 16-top). Then, it remains for a while in this configuration, as indicated by the "spring stay contracted" label, up to the end of the pink area. In this phase, the door stays open while the active 
spring cools in a natural convection regime. When it reaches $40{ }^{\circ} \mathrm{C}$ the antagonistic device is activated. This temperature was considered a good compromise between two opposite requirements. The necessity of starting the deactivation cycle as soon as possible demanded a rapid activation of the other element to reverse the process. On the other hand, the lower the austenite percentage is within the left spring (and, thus, its temperature), the lower is the force, necessary to reset the system. In this second phase, the door closes and the positioner moves back. At this point, the system is ready for another operation.
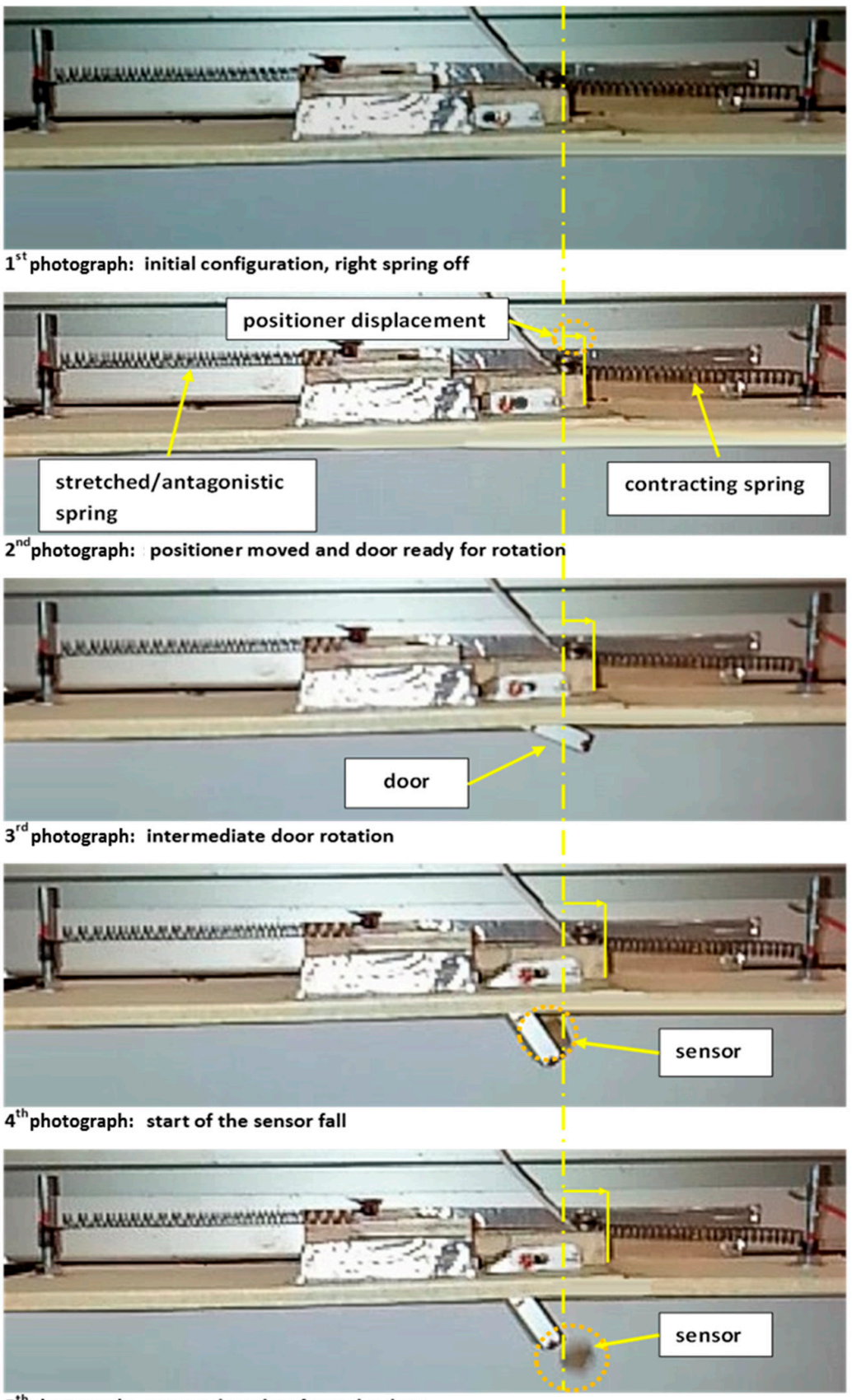

$5^{\text {th }}$ photograph: sensor detaches from the door

Figure 15. Photograph sequence of sensor release.

Time diagram, Figure 17, gives a measure of the process repeatability. During the experiment, a max negative angle of $76^{\circ}$ was found, in good agreement with the numerical predictions and the specifications. The same cycles are reported in Figure 18, on the displacement-rotation plane. A plateau ranging from about 0 to $4 \mathrm{~mm}$ is evident at the top of the graph, corresponding to the phase when 
the door remains closed. Both the positioner translation and the total cycle extension are in good agreement with the numerical predictions, previously shown in Figure 9 (abscissa distance between the "initial equilibrium condition" and the "door opening start" or the "required opening angle of $75^{\circ}$ " points, respectively).
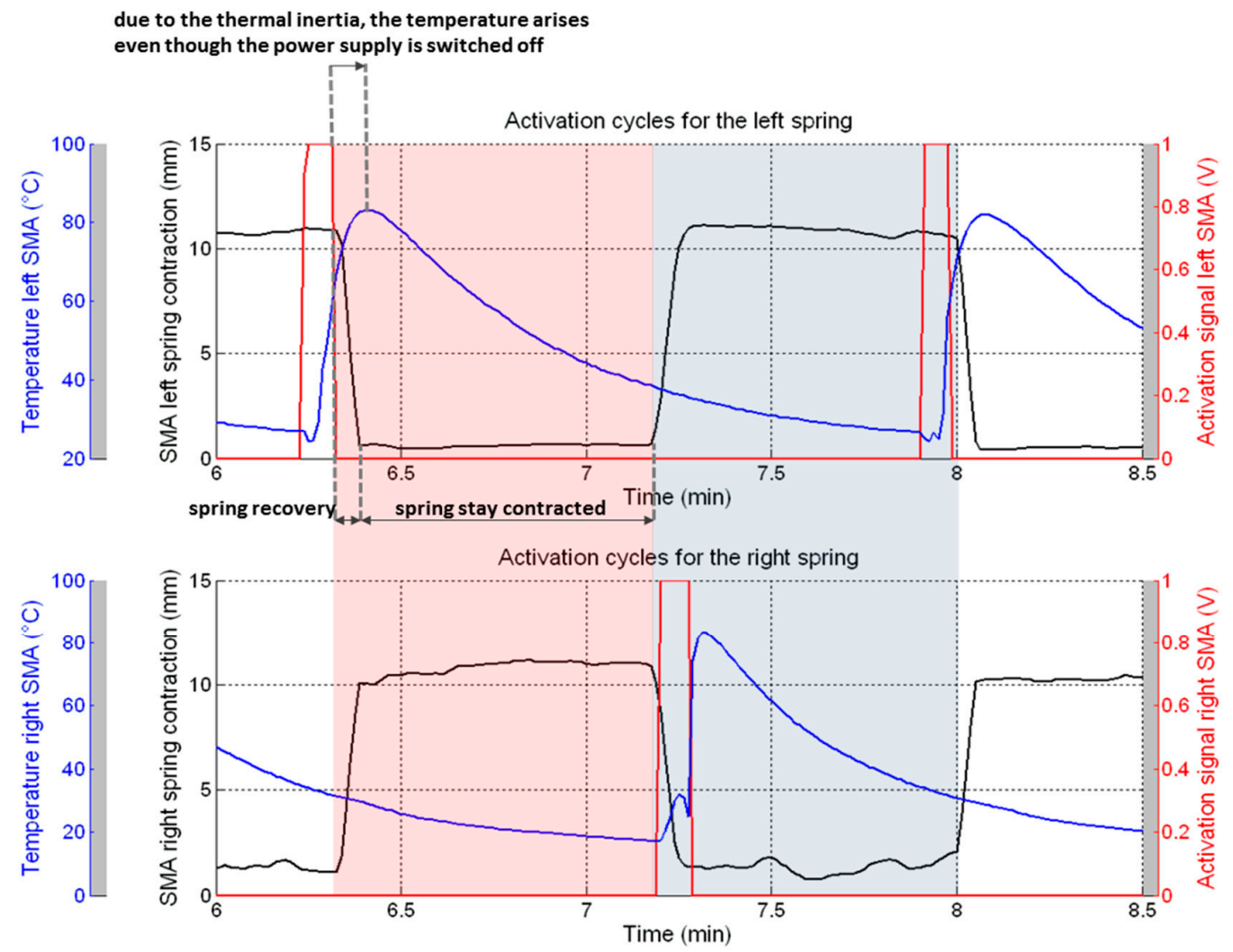

Figure 16. Springs activation vs. time: activation signal (red), temperature (blue), and displacement (black).

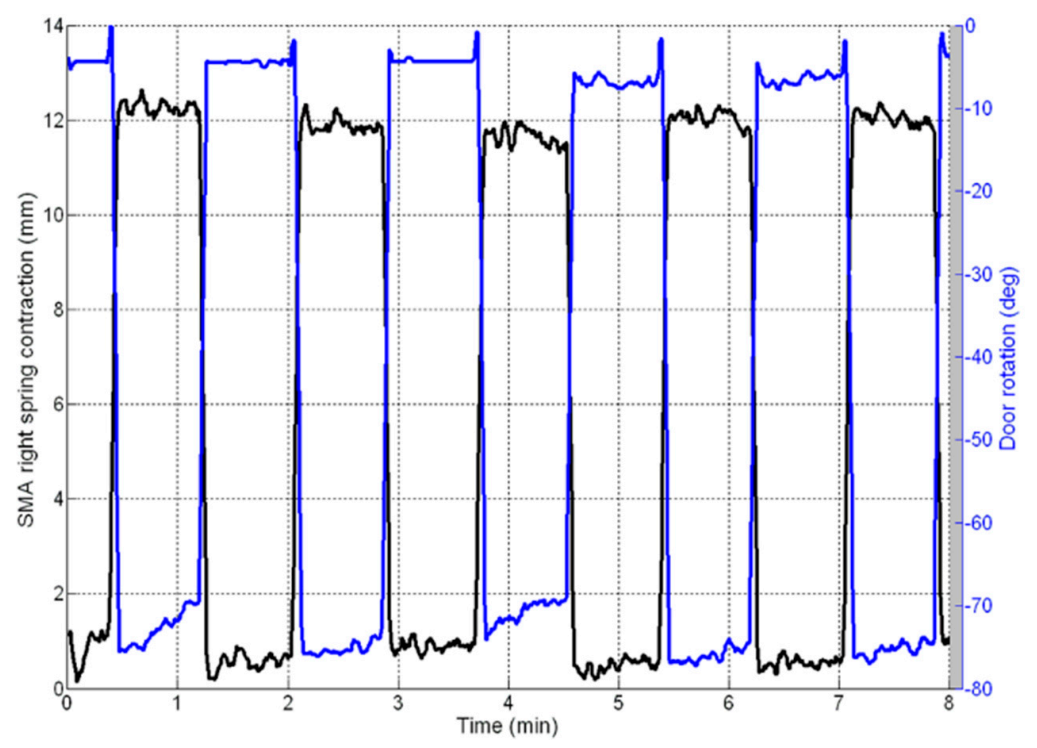

Figure 17. Five activation cycles: right spring contraction (black) vs. door rotation (blue) vs. time. 


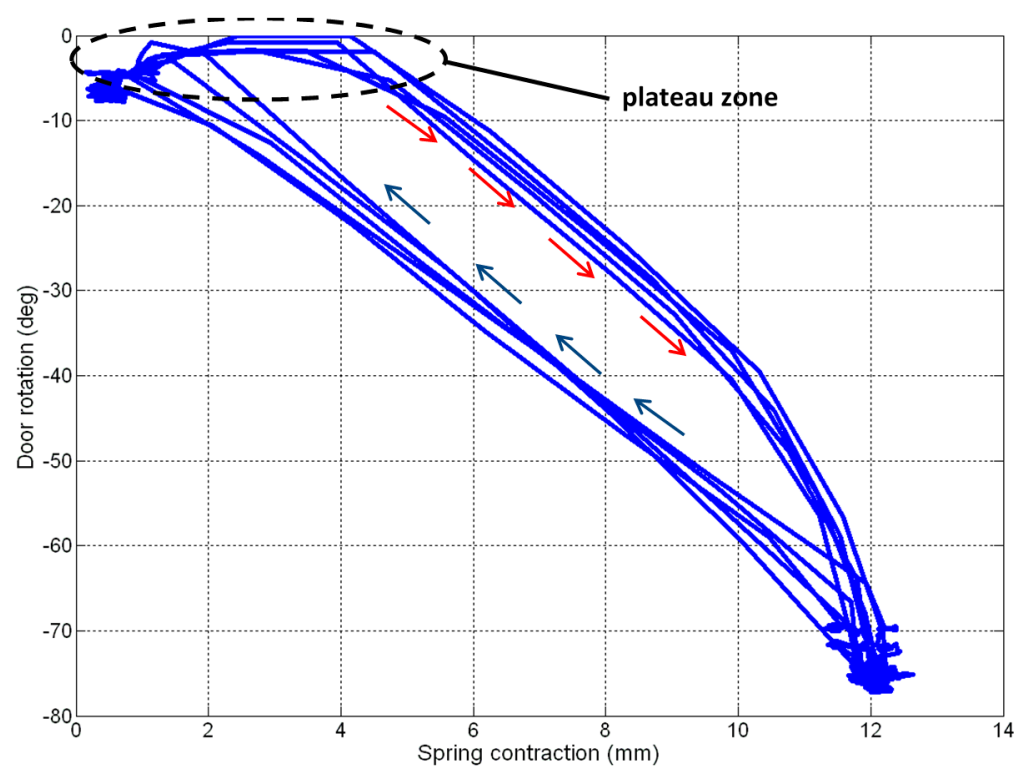

Figure 18. Five activation cycles: door opening and closing (red and blue arrows).

A summary and a comparison of the main parameters (numerical and experimental) is provided in Table 4. From those data, it resulted that a good agreement was found for the kinematic parameters: door opening angle $\left(75^{\circ}\right.$ vs. $\left.76^{\circ}\right)$, spring total contraction (12 vs. $\left.10.5 \mathrm{~mm}\right)$, and spring partial contraction until the opening start ( $4 \mathrm{vs} .3 .7 \mathrm{~mm}$ ). These deviations, due to gaps and free play angles among the system components, can then be easily explained and could be recovered in a controlled realization process.

Table 4. Numerical predictions vs experimental outcomes.

\begin{tabular}{ccccc}
\hline Type of Extimate & $\begin{array}{c}\text { Door Max } \\
\text { Opening Angle }\left(^{\circ}\right)\end{array}$ & $\begin{array}{c}\text { Spring Total } \\
\text { Contraction }(\mathbf{m m})\end{array}$ & $\begin{array}{c}\text { Spring Contraction } \\
\text { before Door } \\
\text { Opening (mm) }\end{array}$ & $\begin{array}{c}\text { Energy Needed for } \\
\text { the Activation of } \\
\text { the Two Springs (J) }\end{array}$ \\
\hline $\begin{array}{c}\text { Numerical prediction } \\
\text { Experimental outcome }\end{array}$ & 75.0 & $12.0^{*}$ & $4.0^{*}$ & $11.8^{* *}$ \\
Delta & $76.0^{* * *}$ & $10.5^{* * *}$ & $3.7^{* * *}$ & $30.0^{* * * *}$ \\
\hline
\end{tabular}

\footnotetext{
${ }^{*}$ Quoted in Figure 5. ${ }^{* *}$ Estimated by computing the mechanical work, occurring to move from the pre-load to the full activated condition (intersections of the blue curve with the black and the red lines, respectively-Figure 9, and assuming a typical SMA mechanical efficiency of 0.01 [40]. *** Averaged values from cycles, plotted in Figure 18. **** Estimated value, assuming that the power was constantly supplied for $5 \mathrm{~s}: 3 \mathrm{~W} \times 5 \mathrm{~s} \times 2$ springs.
}

On the contrary, a larger deviation was observed on the energy estimate per cycle, necessary to drive the SMA springs (11.8 vs. $30.0 \mathrm{~J}$ ). The numerical prediction was obtained by dividing the mechanical work for stretching the antagonistic element (geometrically represented by the area under the blue line in Figure 5, between the pre-load and the fully activated conditions) by the characteristic efficiency of 1\% [40]. The experimental value was instead derived by multiplying the fed power by the dispensing time (5 s). Different factors may concur to this deviation: first, the imperfections in this preliminary realization; second, the friction among the different parts; third, the generic dispersions (electrical and mechanical) of the complete system with the surrounding environment. Substantial improvements are then expected when more sophisticated prototypes will be released.

\section{Performance vs. Specifications}

The work presented herein is completed by performing a synthetic comparison between the specified (Section 2) and the predicted and demonstrated performance. Data was organized in Table 5. It was aimed at giving a synoptic view of the results for the convenience of the researchers and the 
readers. It highlights possible future improvements and deals with the possible drawbacks of the investigated concept.

Table 5. Performance vs. specifications.

\begin{tabular}{|c|c|c|c|c|}
\hline Specifications-Performance & System Size (mm) & Sensor Size (mm) & $\begin{array}{l}\text { System Weight } \\
\text { (No Sensors) (g) }\end{array}$ & Power Supply (W) \\
\hline Requirements & $\leq 100 \times 30 \times 54$ & $\geq 10 \times 2 \times 4=80 \mathrm{~mm}^{3}$ & $\leq 60$ & $\leq 15$ \\
\hline Achieved performance & $99 \times 30 \times 40$ & $\overline{10} \times 10 \times 4=400 \mathrm{~mm}^{3}$ & 28 & 6 \\
\hline Delta & $1 \times 0 \times 14$ & $320 \mathrm{~mm}^{3}$ & 32 & 9 \\
\hline Improvement/worsening ( $\uparrow$ or $\downarrow$ ) & $\uparrow$ & $\uparrow$ & $\uparrow$ & $\uparrow$ \\
\hline
\end{tabular}

Finally, to have an idea of the performance of the SMA actuator with respect to a conventional system used for similar applications (deployment of landing gear of aircraft models, door opening, etc.) [44] a comparison was organized in Table 6.

Table 6. Performance comparison with a conventional actuator.

\begin{tabular}{ccccc}
\hline Type of Actuator & Weight $(\mathbf{g})$ & Volume $\left(\mathbf{c m}^{3}\right)$ & Power (W) & $\begin{array}{c}\text { Number of Sensors Potentially } \\
\text { Simultaneously Releasable ** }\end{array}$ \\
\hline Conventional servo-actuator & 39.5 & 55.4 & 1.5 & 10.0 \\
SMA actuator ${ }^{*}$ & 1.0 & 1.2 & 3.0 & 5.0 \\
\hline$*$ Comprehensive of both the springs. ${ }^{*}$ Computed as the ratio between the power supply available $(15 \mathrm{~W}$ Table 5,
\end{tabular}

${ }^{*}$ Comprehensive of both the springs. ${ }^{* *}$ Computed as the ratio between the power supply available (15 W, Table 5, first row) and the power consumed per cycle.

\section{Conclusions and Further Steps}

In the work at hand the conceptual design and validation of an SMA-based sensor release system for a small UAS was presented. The device was made of a kinematic chain, converting the translational movement of the SMA actuator into the rotation of the fuselage door, allowing the release of sensors and assuring the synchronization among the different movements.

After a preliminary schematic was defined, a suitable theoretical model was prepared to link the main system (allowable spring elongation, spring contraction, and so on) to the characteristic SMA parameters (activation temperatures). The model allowed sizing the different components. Its schematic permitted evaluating the adequacy of the synchronization level for properly positioning the sensor onto the expulsion path and timely opening of the panel. The antagonistic device assured the motion reversibility so to perform cyclic operations in order to release many sensors. A preliminary prototype was finally realized to validate the design process and verify the developed concept. Functionality tests proved the capability of the system to perform the established work and verified the correlation among the main operational parameters (temperatures, door rotation, etc.).

Moving from these results and the coherence with the established requirements, an advanced design was planned. This new phase was conceived to define the constructive details in order to optimize the system performance before initiating a flight test campaign of characterization and validation in operational conditions. The device integration on-board should be faced by outlining the required interfaces to avoid any interference and to assure the adequate power supply and the coordination with the other existing subsystems. The flight tests are envisaged to be conducted during a typical mission, in the cruise phase at a selected altitude. The main scope of the tests is to demonstrate the effective system ability to match the prescribed operational specifications (for instance, release the sensors according to a prescribed sequence) in clean and perturbed conditions with the ultimate objective to identify the viable flight envelope. 
Acknowledgments: This work was developed by the Italian Defence Ministry, in the framework of the Military National Research Program (MNRP) and under the contract CIRA-POI-11-0495, related to activities performed within the Small Unmanned Aerial System design and development. Moreover, the authors would like to recall that the DSC diagram of Figure $8 \mathrm{~b}$ has been provided by Giovanni Cosentino, Innovative Materials Division of CIRA.

Author Contributions: Lorenzo Pellone identified the working principle of the system for releasing the sensors and managed the integrated Digital Mock-Up giving specific suggestions for the system layout. Salvatore Ameduri dimensioned the SMA based sensor release system and organized the experimental functionality campaign. Moving from the UAS needs, Nunzia Favaloro produced the point specifications for the deploying system and provided benchmark info (conventional actuation system). Antonio Concilio provided hints on SMA applications as derived from the related studies and the design approach.

Conflicts of Interest: The authors declare no conflict of interest.

\section{Abbreviations}

$a$

A

A

AC

Af

As

b

B

B

BC

C

C length of the sliding element (Figure 7)

opening panel pivot (Figure 7)

equilibrium state at temperature T1 (Figure 10)

rigid connection between the opening panel and the sliding segment (Figure 7)

austenite finish temperature: temperature at which, without applied loads, the transformation of martensite into austenite ends

austenite start temperature: temperature at which, without applied loads, the

transformation of martensite into austenite starts

length of the rigid connection $\mathrm{AC}$

connection between the active and the antagonistic springs

equilibrium state at temperature T3 (Figure 10)

sliding element (Figure 7)

hinge connection

equilibrium state achieved after the activation of the antagonistic spring (Figure 10)

Computer Aided Design

center of gravity

center of gravity of the opening panel

slot length of the sliding element (Figure 7)

spring wire diameter

winding diameter

direct current

Department of Defense

Differential Scanning Calorimetry

Austenite Young modulus

European Cooperation Space Standardization

Martensite Young modulus

Environmental Sensor Spreader

applied force (Figure 10)

force given by the active spring

reaction of the antagonistic spring

vertical distance between the points A and C (Figure 7)

spring rigidity

martensite finish temperature: temperature at which, without applied loads, the

transformation of austenite into martensite ends

Military National Research Program

martensite start temperature: temperature at which, without applied loads, the

transformation of austenite into martensite starts

Non-Methane Volatile Organic Compounds

residual of Equation (2)

R-phase finish temperature: temperature at which, without applied loads, the transformation of austenite into R-phase ends

R-phase start temperature: temperature at which, without applied loads, the transformation of austenite into R-phase starts

distance between the center of gravity of the opening door and its pivot, A

Remotely Piloted Aircraft 
linear displacement of the active and antagonistic springs

dummy variable for s, used in the definite integral of Equation (5)

Super Elastic

Shape Memory Alloy

Small Unmanned Aerial System

temperature

initial temperature (Figure 10)

intermediate temperature (Figure 10)

final warmed temperature (Figure 10)

Technology Readiness Level

Unmanned Aerial Systems

Unmanned Aerial Vehicle

Weight of the opening door

horizontal displacement of the point B (Equation (3))

Young modulus

strain (Figure 10)

angle between segment $\mathrm{AC}$ and the horizontal line during the opening of the panel

(Figure 7)

dummy variable for $\theta$, used in the definite integral of Equation (5)

initial angle between segment AC and the horizontal line (Figure 7)

Poisson modulus

martensite fraction

stress (Figure 10)

angle between the sliding element, $\mathrm{BC}$, and the horizontal line (Figure 7)

\section{References}

1. Cai, G.; Chen, B.M.; Lee, T.H. An overview on development of miniature unmanned rotorcraft systems. Front. Electr. Electron. Eng. China 2010, 5, 1-14. [CrossRef]

2. Nagy, A.; Rohacs, J. Unmanned Measurement Platform for Paragliders. In Proceedings of the 28th International Congress of the Aeronautical Sciences, Brisbane, Australia, 23-28 September 2012.

3. Eschmann, C.; Kuo, C.-M.; Kuo, C.-H.; Boller, C. Unmanned Aircraft Systems for Remote Building Inspection and Monitoring. In Proceedings of the 6th European Workshop on Structural Health Monitoring, Dresden, Germany, 3-6 July 2012.

4. Jacob, J.; Smith, S.; Cadogan, D.; Scarborough, S. Expanding the Small UAV Design Space with Inflatable Wings; Society of Autmotive Engineers Inc.: Warrendale, PA, USA, 2007.

5. Carpenter, B.; Lyons, J. Lightweight Flexible Solar Array Experiment Summary, NASA Report. 2001. Available online: http://www.eoc.csiro.au/hswww/oz_pi/techforum/Validation_Reports/LFSA.pdf (accessed on 28 November 2016).

6. Petry, G.; Behr, R. The Parafoil Technology Demonstration Project (PTD) lesson learned and Future Visions. In Proceedings of the 15th CEAS/AIAA Aerodynamic Decelerator Systems Technology Conference, Toulouse, France, 9-11 June 1999.

7. Yanushevsky, R. Guidance of Unmanned Aerial Vehicles; CRC Press: Boca Raton, FL, USA, 2011.

8. Cai, G.; Dias, J.; Seneviratne, L. A Survey of Small-Scale Unmanned Aerial Vehicles: Recent Advances and Future Development Trends. Unmanned Syst. 2014, 2, 1-25. [CrossRef]

9. Gupta, A.K.; Arora, S.K. Industrial Automation and Robotics; LAXMI Publications (P) Ltd.: New Delhi, India, 2007.

10. Tai, K.; El-Sayed, A.-R.; Shahriari, M.; Biglarbegian, M.; Mahmud, S. State of the Art Robotic Grippers and Applications. Robotics 2016, 5, 11. [CrossRef]

11. Lecce, L.; Concilio, A. Shape Memory Alloy Engineering: For Aerospace, Structural and Biomedical Applications; Butterworth-Einemann, Elsevier Science: Oxford, UK, 2014.

12. Liang, C.; Rogers, C.A. A multi-dimensional constitutive model for shape-memory alloys. J. Eng. Math 1992, 26, 429-443. [CrossRef]

13. Huang, M.S.; Brinson, L.C. A multivariant model for single crystal shape memory alloy behavior. J. Mech. Phys. Solids 1998, 16, 1379-1409. [CrossRef]

14. Patoor, E.; Lagoudas, D.C.; Entchev, P.; Brinson, L.C.; Gao, X. Shape-memory alloys, part I: General properties and modeling of single crystal. Mech. Mater. 2006, 38, 391-429. [CrossRef] 
15. De Aguiar, R.A.A.; de Castro Leão Neto, W.C.; Savi, M.A.; Calas Lopes Pacheco, P.M. Shape Memory Alloy Helical Springs Performance: Modeling and Experimental Analysis. Mater. Sci. Forum 2013, 758, 147-156. [CrossRef]

16. Yates, S.J.; Kalamkarov, A.L. Experimental Study of Helical Shape Memory Alloy Actuators: Effects of Design and Operating Parameters on Thermal Transients and Stroke. Metals 2013, 3, 123-149. [CrossRef]

17. Villa, T.; Gonzalez, F.; Miljievic, B.; Ristovski, Z.D.; Morawska, L. An Overview of Small Unmanned Aerial Vehicles for Air Quality Measurements: Present Applications and Future Prospectives. Sensors 2016, 16, 1072. [CrossRef] [PubMed]

18. Adam Savage's tested. Available online: http://www.tested.com/tech/524313-how-get-hobby-rc-testingwise-stabilization/ (accessed on 10 June 2016).

19. RC Group. Available online: http://www.rcgroups.com/forums/showthread.php?t=2260078 (accessed on 20 March 2016).

20. Thing Novation. Available online: http://thingnovation.com/aluminium-robot-clamp-gripper-roboticarduino-garra-brazo-arm-pinza-2-dof.html?__store=en (accessed on 6 February 2016).

21. Thingiverse. Available online: http:/ / www.thingiverse.com/thing:14190 (accessed on 2 July 2016).

22. Robotshop. Available online: http://www.robotshop.com/en/actobotics-horizontal-standard-gripper-kit-a. html (accessed on 13 September 2016).

23. Pollard, E.L.; Jenkins, C.H.M. Shape Memory Alloy Deployment of Membrane Mirrors for Spaceborne Telescopes. J. Spacecr. Rocket. 2007, 44, 1. [CrossRef]

24. Jacobs, S.; Coconnier, C.; Di Maio, D.; Scarpa, F.; Toso, M.; Martinez, J. Deployable auxetic shape memory alloy cellular antenna demonstrator: Design, manufacturing and modal testing. Smart Mater. Struct. 2012, 21, 1-12. [CrossRef]

25. Calkins, F.T.; Mabe, J.H. Shape Memory Alloy Based Morphing Aerostructures. J. Mech. Des. 2010, 132, 111012. [CrossRef]

26. Sofla, A.Y.N.; Elzey, D.M.; Wadley, H.N.G. Shape morphing hinged truss structures. Smart Mater. Struct. 2009, 18, 1-8. [CrossRef]

27. Unsworth, J.D.; Waram, T.C. Shape Memory Alloy Tubular Deployment System. U.S. Patent 5,846,247, 8 December 1998.

28. Dayananda, G.N.; Varughese, B.; Rao, M.S. Shape Memory Alloy Based Smart Landing Gear for an Airship. J. Aircr. 2007, 44, 1469-1477. [CrossRef]

29. Unmanned Aerial Vehicles Reliability Study. Available online: http://www.uadrones.net/military/ research/acrobat/0302.pdf (accessed on 6 December 2003).

30. Abdullah, E.J.; Bil, C.; Watkinsm, S. Testing of Adaptive Airfoil for UAV using Shape Memory Alloy Actuators. In Proceedings of the 27th International Congress of the Aeronautical Sciences, Nice, France, 19-24 September 2010.

31. Ameduri, S.; Concilio, A.; Favaloro, N.; Pellone, L. A Shape Memory Alloy Application for Compact Unmanned Aerial Vehicles. Aerospace 2016, 3, 16. [CrossRef]

32. Madhani, A.J. Robot Hand with Human-Like Fingers. EP Patent 2,239,106 B1, 14 March 2012.

33. Chaitanya, S.K.; Dhanalakshmi, K. Design and investigation of a shape memory alloy actuated gripper. Smart Struct. Syst. 2014, 14, 4541-4558.

34. Clausi, D.; Gradin, H.; Braun, S.; Peirs, J.; Stemme, G.; Reynaerts, D.; van der Wijngaart, W. Robust actuation of silicon MEMS using SMA wires integrated at wafer-level by nickel electroplating. Sens. Actuators A 2013, 189, 108-116. [CrossRef]

35. Bundhoo, V.; Haslam, E.; Birch, B.; Park, E.J. A shape memory alloy-based tendon-driven actuation system for biomimetic artificial fingers, part I: Design and evaluation. Robotica 2009, 27, 131-146. [CrossRef]

36. Prapaipittayakhun, K.; Srituravanich, W.; Pimpin, A. Shape Memory Alloy Micro-Actuator for Handling of Head Gimbal Assembly. Aijstpme 2011, 4, 1-8.

37. Machado, L.G.; Savi, M.A. Medical applications of shape memory alloys. Braz. J. Med. Biol. Res. 2003, 36, 683-691. [CrossRef] [PubMed]

38. Pecora, R.; Iannuzzo, G.; Riccio, M.; Russo, S.; Calvi, E.; Lecce, L.; Barbarino, S.; Concilio, A.; Ameduri, S. Actuator Device Based on a Shape Memory Alloy, and a Wing Flap Assembly Fitted with Such an Actuator Device. U.S. Patent 8,348,201 B2, 8 January 2013. 
39. Jani, J.M.; Leary, M.; Subic, A. Shape Memory Alloys in Automotive Applications. Appl. Mech. Mater. 2014, 663, 248-253. [CrossRef]

40. Huber, J.E.; Fleck, N.A.; Ashby, M.F. The selection of mechanical actuators based on performance indices. Proc. R. Soc. Lond. A 1997, 453, 2185-2205. [CrossRef]

41. Barooah, P. System and Method for Controlling Shape Memory Alloy Actuators. U.S. Patent 6,543,224 B1, 8 April 2003.

42. Ghomshei, M.M.; Khajepour, A.; Tabandeh, N.; Behdinan, K. Finite Element Modeling of Shape Memory Alloy Composite Actuators: Theory and Experiment. J. Intell. Mater. Syst. Struct. 2001, 12, 761-773. [CrossRef]

43. Serry, M.Y.; Moussa, W.A.; Raboud, D.W. Finite-element modeling of shape memory alloy components in smart structures, part II: Application on shape-memory-alloy-embedded smart composite for self-damage control. In Proceedings of the International Conference on MEMS, NANO and Smart Systems, Banff, AB, Canada, 23 July 2003.

44. Hobby Modellismo. Available online: http://www.hobbymodellismo.com/it/carrello-retrattile-elettricolaterale-dy1023 (accessed on 6 July 2016).

(C) 2017 by the authors; licensee MDPI, Basel, Switzerland. This article is an open access article distributed under the terms and conditions of the Creative Commons Attribution (CC BY) license (http://creativecommons.org/licenses/by/4.0/). 